\begin{tabular}{cc}
\hline & $\begin{array}{c}\text { International Journal of Health Services } \\
\text { Research and Policy } \\
\text { INESEG }\end{array}$ \\
INTERNATIONAL & e-ISSN: $2602-3482$ \\
ENGINEERING & \\
SCIENCE AND & IJSRark.org.tr/ijhsrp \\
EDUCATION GROUP & HSP \\
\hline
\end{tabular}

Research Article

\title{
THE EFFECTS OF CARE-GIVING UPON FAMILY MEMBERS OF INDIVIDUALS WHO ARE TREATED IN THE PALLIATIVE CARE UNIT: A PHENOMENOLOGICAL APPROACH
}

\author{
Derya Bıçak Ayık ${ }^{1}$ (D) Sibel Şentürk ${ }^{* 2}$ (D) \\ ${ }^{1}$ Department of Nursing, Istanbul University-Cerrahpasa, Institute of Graduate Students, Florence Nightingale \\ Nursing Faculty, İstanbul, Turkey \\ ${ }^{2}$ Department of Nursing, Bucak Health School, Burdur Mehmet Akif Ersoy University, Bucak-Burdur, Turkey. \\ *Corresponding author; sibelsenturk@mehmetakif.edu.tr
}

\begin{abstract}
Caregiving family members are individuals who are directly involved in the care of a lifethreatening patient, often facing a wide range of tasks, such as physical care, providing emotional support, and taking part in the treatment process. This research was carried out to determine the effects of caregiving upon family members of individuals who are treated in the palliative care unit. This descriptive phenomenological qualitative study was conducted with 16 family members who had been taking primary care of patients for at least three months and agreed to participate in the study. The data were collected in 35-40 minutes by face-to-face interview with a semi-structured interview form. Colaizzi's phenomenological data analysis method was used in the evaluation of the data, and 5 themes were determined. Family members participating in the research stated that they experienced physiological problems such as pain, sleep problems, and fatigue; psychological problems such as stress and fear; economic problems due to job losses and treatment costs; social problems for reasons such as isolation and problems in family relations such as a change in roles and communication disruption. As a result of the research, it was determined that especially all of the family members had psychological and social problems. The problems and needs of family members should be questioned in clinical settings, and they should be directed to support units.
\end{abstract}

Keywords: Palliative care, Family member, Experience, Phenomenological Approach.

\begin{tabular}{ll}
\hline Received: May 14, 2020 & Accepted: June 18, 2020 \\
\hline
\end{tabular}

\section{Introduction}

Palliative care is an approach to improve the quality of life of the patient and their family, who are faced with a life-threatening disease, and it is considered as the right of every individual and aims to detect and treat physical, psychosocial, and spiritual problems, especially pain, in the early period [1], [2]. This type of care includes a team-based approach that helps to manage the patient's disturbing symptoms, to coordinate care, and to set care objectives by including not only the patient but also family members [3]. 
Caregiving family members are individuals who are directly involved in the care of a lifethreatening patient, often facing a wide range of tasks, such as physical care, providing emotional support, and taking part in the treatment process [4]. In this process, family members pay attention to the patient's drug management, constantly provide psychological support to the patient, and provide personal care of the patient [5-7]. However, many caregiving family members are unprepared for the caregiving role and have limited knowledge that may affect the nature and quality of care provided [4]. Family members who are unprepared to take on the responsibilities brought by the care become very weak against the progress of the disease and the consequences of the process [3]. Increasing symptoms in patients increase stress and care burden, especially in family members living with the patient [5-8]. Studies have shown that family members who care for a patient with a life-threatening illness experience physical health problems such as joint pain, headache, indigestion, and dizziness, as well as fatigue and sleep disorders due to care burden and insufficient sleep [6], [9], [10-11].

However, family members may experience psychosocial problems as they are also affected by the patient's care [9]. Among the psychological problems experienced by family members of patients receiving palliative care, in general, are emotional problems such as anxiety, depression, post-traumatic stress disorder symptoms, tension, helplessness, uncertainty, guilt, anger, fear, and hopelessness [9], [12-13]. Family members also face social isolation and occupational problems as a result of financial problems, restriction of time, and freedom during the care phase [5], [9]. It has also been emphasized that the caregivers have problems in their relations with their spouse and family as well as home life [4]. It is stated in the studies conducted that these problems experienced in the process of providing care may increase the burden of family members and cause them not to meet or delay their own health needs [14-15]. All these physical, social, mental, and financial problems experienced by the family members are alarming as they can reduce the quality of life of the caregiver and threaten their ability [12].

It is among the responsibilities of the palliative care nurse to pay attention to and alleviate the problems experienced by the family members [5]. However, healthcare professionals are either often reluctant to evaluate family members or consider them a time-consuming task [11]. As can be seen, despite the serious care burdens of family members, their problems and needs are rarely questioned in the clinical setting [16]. In addition, only a few studies directly examined the problems experienced by family members who care for inpatients in the palliative care unit [2-3], [5], [9], [14]. To examine indepth experiences of the caregiving process among family members of those who are treated the palliative care unit is important to determine actual needs during this process and to plan care services targeting these needs.

This research was carried out to determine the effects of giving care for family members of individuals who are treated in the palliative care unit.

\section{Methods}

\subsection{Study Design}

The research is planned as a descriptive phenomenological qualitative study.

\subsection{Setting and Sample}

The population of this study consisted of the family members of the individuals who received inpatient treatment at the Palliative Care Unit (PCU) of Gazi Yaşargil Training and Research Hospital of Diyarbakır University of Health Sciences. Purposive sampling and snowball sampling methods were 
used in recruiting the study group. In purposive sampling, the characteristics of those to be included in the study were identified. The sample consisted of a total of 16 family members who (a) undertook primary care of patients for at least three months, (b) residing in Diyarbakır Province, (c) were 18 years of age and over, (d) had no communication and perception problems (e) can understand and speak Turkish, and (f) agreed to participate in the study. Snowball sampling was used in achieving the studysample. Through snowball sampling, a participant is recruited out of the study-population through interviews and this participant recruits the second one and the second participant recruits the third one; in this manner, the number of the study-sample is increased and the study-sample is enlarged. In descriptive phenomenological qualitative research, no rules have been determined regarding the number of samples, and research is conducted with a small number of sample groups limited to 5 to 25 participants in qualitative studies in which in-depth interviews are held. However, it is known that when the answers of the participants in the sample of the research start to be similar to each other, the research reaches the saturation point and the data collection process is stopped [17]. The study was based on data saturation and interviews were terminated after the $16^{\text {th }}$ individual interview.

\subsection{Data Collection}

The data were collected by conducting various in-depth individual interviews via a semistructured questionnaire using a face-to-face interview method. The interviews were held between April 24 and May 8, 2020, when family members for any reason. After obtaining the verbal and written consent of the individuals who agreed to participate in the study, a suitable date and time were determined for face-to-face individual interviews. Due to the Covid-19 pandemic process, the researchers interviewed family members on skype on the specified day and time. Before starting the interviews, the research protocol was explained. For the interviews to be conducted in a healthy way, the interviews were held in a quiet and quiet room determined by researchers and family members between 35-40 minutes. During the interviews, other family members in the house were informed that they should not enter the interview room. During the interviews, statements of family members were recorded with a voice recorder, and notes were taken where necessary. Family members were also asked to convey their feelings and thoughts in writing and by e-mail to better express their feelings. In total, there were made three interviews.

\subsubsection{Instruments}

The data in this study were collected through a semi-structured interview form [4-5], [7-9], [13], [18-19] prepared by the researchers by reviewing the literature, examining the characteristics of family members. A total of 14 questions including 7 questions (age, gender, marital status, educational status, occupation, disease type, duration of treatment in the palliative care unit) related to individuals who were given care, and 7 other questions (age, gender, marital status, educational status, occupation, the degree of relation, how long the person has been giving care) are in the first part of the interview form. In the second part, 3 open-ended questions covering general areas and not directing were asked to identify the problems experienced by family members. Open-ended questions addressed to the family members in the study are listed as, 'What does it mean to you to have a family member lying in a palliative care unit?', 'What kind of changes does caring for a family member lying in the palliative care unit bring to your life?', and 'What are the difficulties you have experienced in providing care to a family member lying in the palliative care unit?' 


\subsection{Ethical Consideration}

Before data collection, Ethics committee approval was gained from the Ethics Committee of Non-Interventional Clinical Studies of Burdur Mehmet Akif Ersoy University (Decision Number: GO 2020/106; Date: 15.4.2020) and oral and written consent was also obtained from the family members, and information was given about the use of the voice recorder, and an assurance was provided about the confidentiality of the voice recording. Participant numbers were used instead of the names in the research report. This research was carried out by considering the Good Clinical Practices of the Helsinki Declaration.

\subsection{Data Analysis}

Colaizzi's seven-step descriptive phenomenological method was used because it provided a systematical analysis of quantitative data obtained from face-to-face interviews with participants and it was often chosen in descriptive phenomenological studies [20]. In the first phase of the data analysis, audio-recordings were one by one listened to by the researchers, were computerized, and were transcribed verbatim. To make sure that audio-transcriptions were correct; original audio-recordings were again listened to and were compared to transcriptions and thus, audio-transcriptions were finalized. Each of these transcriptions was entered into the NVivo 8 computer program and was again read by the researchers. In the second phase, significant and relevant statements were marked. In the third phase, statements marked were again read and their real meanings were explored. In the fourth phase, these meanings explored were categorized under certain theme clusters. In the fifth phase, the findings were combined to define phenomena comprehensively and a detailed explanation of findings and real-life experiences was written. In the sixth phase, researchers reduced the detailed explanations to a short statement that -they thought- caught aspects important to phenomena. In the final phase, researchers again interviewed the participants to verify whether or not transcribed statements included participants' real experiences and their feedbacks were obtained [Figure 1].

- Read all the participants' description of the phenomenon under study

-Extract significant statements that pertain directly to the phenomena

-Formulate the meaning of these significant statements

- Categorize the formulated meaning into clusters of themes

-Integrate findings into an exhaustive description of the phenomenon being studied

-Validate the exhaustive description by returning to some of the participants to ask them how it compares to their experiences.

-Incorporate any changes offered by the participants into the final description of the essence of the phenomenon.

Figure 1: Colaizzi's phenomenological data analysis steps. 


\subsubsection{Validity and Reliability Studies}

Various validity and reliability studies related to data analysis were also carried out. In this context, to ensure reliability in qualitative research, the participants were asked to read the transcripts of their interview records and to confirm that their opinions were transferred correctly. This method, which Lincoln and Guba have named as member's check, is intended to provide internal validity and reliability. Also, two academics experienced in the field of qualitative research were asked for the analysis (assignment of codes and codes to themes) by the researchers on the data transferred to the transcription. In this context, this reliability study, called peer debriefing by Miles and Huberman, was also carried out [21].

\subsection{Research Limitations}

The findings obtained are limited only to the opinions of the 16 family members participating in the research and cannot be generalized due to the fact that this study was carried out with a descriptive phenomenological qualitative research technique.

\section{Results}

Half of the family members participating in this study were male and sons of these patients, with 1-5 years of caregiving experience; the vast majority of them were primary school graduates and single (Table 1).

Table 1. Demographic characteristics of family members

\begin{tabular}{llllllll}
\hline Code & Age & Gender & Education Status & $\begin{array}{l}\text { Marital } \\
\text { status }\end{array}$ & Job & $\begin{array}{l}\text { The degree of } \\
\text { proximity }\end{array}$ & $\begin{array}{l}\text { Duration of } \\
\text { care }\end{array}$ \\
\hline $\mathbf{1}$ & 30 & M & Undergraduate & Married & Civil servant & Son & $1-5$ years \\
$\mathbf{2}$ & 45 & F & Undergraduate & Single & Unemployed & Daughter & 10 years and $\uparrow$ \\
$\mathbf{3}$ & 29 & F & Primary education & Single & Housewife & Sibling & 1 year $\downarrow$ \\
$\mathbf{4}$ & 55 & M & Primary education & Married & Retired & Son & 1 year $\downarrow$ \\
$\mathbf{5}$ & 20 & F & Undergraduate & Single & Unemployed & Daughter & $1-5$ years \\
$\mathbf{6}$ & 40 & M & Primary education & Married & Unemployed & Son & $1-5$ years \\
$\mathbf{7}$ & 28 & F & Undergraduate & Single & Worker & Daughter & $1-5$ years \\
$\mathbf{8}$ & 41 & M & Primary education $\downarrow$ & Married & Worker & Son & 1 year $\downarrow$ \\
$\mathbf{9}$ & 34 & M & Primary education & Married & Unemployed & Son & $1-5$ years \\
$\mathbf{1 0}$ & 62 & F & Primary education $\downarrow$ & Married & Housewife & Spouse & $1-5$ years \\
$\mathbf{1 1}$ & 20 & F & Primary education & Single & Unemployed & Daughter & $1-5$ years \\
$\mathbf{1 2}$ & 23 & M & Undergraduate & Single & Civil servant & Nephew/Niece & 1 year $\downarrow$ \\
$\mathbf{1 3}$ & 30 & F & Primary education & Single & Housewife & Sibling & $1-5$ years \\
$\mathbf{1 4}$ & 40 & F & Primary education $\downarrow$ & Single & Housewife & Daughter & $1-5$ years \\
$\mathbf{1 5}$ & 19 & M & Primary education & Single & Unemployed & Son & $11-5$ years \\
$\mathbf{1 6}$ & 20 & M & Undergraduate & Single & Student & Son & $1-5$ years \\
\hline
\end{tabular}

The vast majority of palliative care patients were male, primary school graduates, married, and cancer patients (Table 2). 
Table 2. Demographic characteristics of palliative care patients'

\begin{tabular}{|c|c|c|c|c|c|c|c|}
\hline Code & Age & Gender & Education Status & $\begin{array}{l}\text { Marital } \\
\text { status }\end{array}$ & Job & Disease & $\begin{array}{l}\text { Duration of } \\
\text { stay in the } \\
\text { palliative } \\
\text { care unit }\end{array}$ \\
\hline 1 & 76 & $\mathrm{M}$ & Primary education & Married & Unemployed & Alzheimer & $2-5$ months \\
\hline 2 & 88 & $\mathrm{~F}$ & Literate & Married & Housewife & Parkinson & 2-5 months \\
\hline 3 & 21 & M & Primary education & Single & Unemployed & Decubitus & $2-5$ months \\
\hline 4 & 89 & $\mathrm{~F}$ & Primary education $\downarrow$ & Married & Retired & Cancer & 1 month \\
\hline 5 & 65 & M & Primary education & Married & Retired & $\begin{array}{l}\text { Cerebrovascular } \\
\text { disease }\end{array}$ & 2-5 months \\
\hline 6 & 75 & M & Primary education $\downarrow$ & Married & Unemployed & Demans & 2-5 months \\
\hline 7 & 59 & M & Primary education & Married & Retired & Cancer & 2-5 months \\
\hline 8 & 75 & M & Primary education & Married & Unemployed & Cancer & 2-5 months \\
\hline 9 & 60 & $\mathrm{M}$ & Primary education $\downarrow$ & Married & Unemployed & Cancer & 1 month \\
\hline 10 & 68 & M & Primary education $\downarrow$ & Married & Unemployed & Heart failure & 1 month \\
\hline 11 & 71 & M & Primary education & Married & Retired & $\begin{array}{l}\text { Celebral } \\
\text { hemorrhage }\end{array}$ & 2-5 months \\
\hline 12 & 50 & $\mathrm{~F}$ & Primary education & Married & Housewife & $\begin{array}{l}\text { Cerebrovascular } \\
\text { disease }\end{array}$ & 1 month \\
\hline 13 & 21 & $\mathrm{~F}$ & Primary education & Single & Unemployed & Diabetes & 1 month \\
\hline 14 & 92 & $\mathrm{~F}$ & Primary education $\downarrow$ & Single & Housewife & Alzheimer & 1 month \\
\hline 15 & 71 & F & Primary education & Married & Retired & $\begin{array}{l}\text { Cerebrovascular } \\
\text { disease }\end{array}$ & $2-5$ months \\
\hline 16 & 73 & $\mathrm{~F}$ & Primary education & Married & Retired & Diabetes & 1 month \\
\hline
\end{tabular}

The main category of the family members participating in the research are the effects of giving care; under a thematic scheme, 5 themes and 10 sub-themes were identified: physical problems (pain, sleep problems, fatigue), psychological problems (stress, fear), economic problems (treatment costs, job losses), social problems (isolation), and family relations (change in roles, communication disruption) (Table 3).

Table 3. Categories and themes resulted from interviews

\begin{tabular}{lll}
\hline Category & Themes & Sub-themes \\
\hline & Physical problems & Pain \\
& & Sleep problems \\
& Psychological problems & Fatigue \\
& Stress \\
Effects of Care-Giving & Economic problems & Fear \\
& & Treatment costs \\
& Social problems & Job losses \\
& Family relationships & Isolation \\
& & Change in roles \\
& & Communication disruption \\
\hline
\end{tabular}

\section{Theme 1: Physical Problems}

The vast majority of the family members participating in the study stated that while they cared for their patients, various diseases occurred or their existing diseases worsened, and they particularly experienced pain, sleep problems, and fatigue. 


\section{Sub-themes 1.1. Pain}

Some of the participant family members stated that their preexisting neck and back pains were aggravated during care-giving whereas some others reported that they had not had preexisting neck, back, and arm pains but suffered from these pains after they started giving care.

- Since I had a herniated disc, I had a lot of difficulty in lifting and lowering the patient. My pain was unbearable (Participant 1).

- I had not had preexisting pains. After I started caring, I had a meniscus and a herniated disk (Participant 2).

- I had a herniated disc for a while, but after I started to care, my pain increased a lot (Participant 6).

\section{Sub-themes 1.2. Sleep problems}

The participant family members stated that they experienced sleep problems because they woke up early due to times to give medicines to those whom they cared for, they could not sleep due to fears that something bad would occur, and their sleep was interrupted due to pains and fatigue experienced during care-giving.

- I cannot sleep fearing that something would happen to my father during sleep. I always feel sleepy during the daytime (Participant 6).

- I have to wake up early to give my wife's medication, so I have constant sleep problems (Participant 10).

\section{Sub-themes 1.3. Fatigue}

The participant family members emphasized that they constantly felt tired because their burden was aggravated by care-giving, they got tired because they frequently had to lift the patients and to put them down during caring and they were unable to rest because there was nobody to provide care.

- Because I alone performed the care for private areas of my father and had him have a bath, I feel exhausted after the care (Participant 6).

- I started feeling very tired after giving care (Participant 7).

- As my workload increased at home, I am constantly tired (Participant 10).

\section{Theme 2: Psychological Problems}

All of the family members who participated in the study stated that they were psychologically affected, that they were constantly in the hospital environment, and that their mood deteriorated when they saw worse patients, they entered a more sensitive mood, and they often experienced stress and fear.

\section{Sub-themes 2.1. Stress}

The participant family members told that their stress level elevated because they were at the hospital all the time, their stress went up because of the behaviors of those to whom they gave care and they underwent stress because they consider themselves inefficient and incompetent about care-giving.

- My father was a difficult patient, and this made me psychologically upset. My father's aggressive and irritated mood caused me to get into a more sensitive mood and stress (Participant 1).

- The most important reason for my sadness was the thought of not being able to catch up with / be enough / effective with my mother's care. These thoughts caused my psychology to deteriorate and my stress level was increasing. (Participant 2).

\section{Sub-themes 2.2. Fear}

The participant family members reported that they had fears because they felt that those to whom they provided care would die due to the disease diagnosis, treatment would fail, and something would happen to the patients during care. 
- Witnessing the discomfort of dozens of people every day affects my psychology. I am very afraid that my father will not be able to recover because he has cancer (Participant 7).

- I am always depressed but my wife's disease affected my psychology further. I have this fear at all times that, something bad will happen while caring for her (Participant 10).

\section{Theme 3: Economic Problems}

The vast majority of the family members participating in the research stated that they experienced financial difficulties, that their costs increased due to special examinations, medical products, and transportation, those sick individuals did not work due to their illnesses, and there was no other person who brings money, and caregivers had to cancel their additional jobs and they experienced job losses due to caregiving.

\section{Sub-themes 3.1. Treatment costs}

The participant family members stated that they took those to whom they provided care to private medical clinics so that they could have better care and treatment, had to buy some medical devices to give home care and their expenses increased because they often bought medical materials because they had to pay attention to hygiene.

- We bought a hospital bed, air mattress, aspiration, and oxygen device to make my father comfortable. I can say that we turned our house into a hospital. I also had expenses for medical products and cleaning supplies (Participant 1).

- I took my mother to better doctors in order to have her examined due to her illness. Of course, it was a bit expensive (Participant 2).

\section{Sub-themes 3.2. Job losses}

The participant family members expressed that they had to change residence places where they used to live in order to give care, therefore lost their jobs and canceled some of their routine affairs because they were obliged to provide care.

- Since we had to go from our district to the city center 3 times a week in the first diagnosis period, the additional jobs I planned before were canceled. Our transportation costs have increased because we are constantly commuting (Participant 1 ).

- I used to work in Istanbul. However, since my father became bed-ridden, I had to quit my job and settle in Diyarbakır. I do not have a job right now, my brothers and sisters are trying to support my expenses (Participant 6).

- I experienced bad situations financially because I left my job (Participant 15).

\section{Theme 4: Social Problems}

All of the family members who participated in the research stated that they did not have any social life because they were always in the hospital, that the people they had social relations with were only relatives who came to visit the hospital, that they had social isolation, and that they could not chat with their friends and do sports right now.

\section{Sub-themes 4.1. Isolation}

The participant family members underlined that they had to restrict visits to relatives and friends, could not go to coffee houses, gyms and shopping-malls due to those to whom they cared; they used to be sociable in the past but now their social relations have weakened or been terminated completely.

- Since my father was bed-ridden, we had to reduce the number of guests so that no infection could develop (Participant 1). 
- I used to go to the coffeehouse and play games with my friends. Now, even when I am with my friends, my mind is always with my father. Therefore, my social relations have decreased considerably (Participant 6).

- Since I spend most of my time in the hospital, I cannot go to the gym and chat with my friends as I used to. I could not continue my social life as I used to... (Participant 16).

\section{Theme 5: Family Relationships}

The vast majority of the family members who participated in the study stated that their family relations deteriorated during the caregiving process, that married people could not spend time with their spouses and children, that sometimes tensions occurred in the family relations and they cannot fulfill their responsibilities regarding their families.

\section{Sub-themes 5.1. Change in roles}

The participant family members emphasized that they could not see their family members and their spouses or children took over the responsibilities that they were supposed to because they stayed together with those to whom they provided care.

- I see my family less because I am always caring for my father. My wife has to deal with children and household chores (Participant 6).

- Since I take care of my father, I cannot spend much time with my wife and children. I cannot organize things (Participant 9).

- My responsibilities have increased. Everyone is constantly asking me about my wife. In addition, I get up early every morning and open the windows for fresh air, clean her room, change the sheets, help her eat her dinner, and give the medicines. I do everything. I am dealing with these routines every day; our family relationships are only about them! (Participant 10).

\section{Sub-themes 5.2. Communication disruption}

The participant family members stated that they sometimes had conflicts and difficulty getting in contact with those to whom they provided care and could not express themselves very well.

- Because my father was bedridden, he sometimes showed aggressive behaviors while I was giving him care; which was sometimes causing me to shout at him and to get angry (Participant 1).

- Since it affects all family members, there is constant tension and stress among the family members (Participant 7).

\section{Discussion}

With the prolonged life span, the population over 65 years of age is increasing and as a result, an increase is observed in patients who require care [4]. Today, care services for such patients have started to shift from healthcare professionals to family members who provide care. In this context, 5 themes were identified as physical problems, psychological problems, economic problems, social problems, and problems in family relations in this study, which was carried out in order to determine the adversities experienced by the family members who are primarily responsible for the care of the individuals who are treated in the palliative care unit.

\section{Theme 1: Physical Problems}

Family members who are responsible for the care of a patient who is in the terminal period or who need long-term care are physically faced with fatigue, headache, indigestion, dizziness, sleep problems, joint pain, and an unhealthy lifestyle [10-11]. Studies have reported that people who care for patients in need of serious attention experience 'primary caregiver syndrome' [6], [10]. This syndrome 
indicates that caregivers experience fatigue, energy loss, lethargy, and exhaustion in this process [6]. In a study conducted with family members who care for cancer patients with glioblastoma brain metastasis lying in the palliative care unit, it was found that more than $50 \%$ of the caregivers had lower well-being, fatigue, and drowsiness [18]. Schreiber-Katz et al. (2014) reported that $88 \%$ of those who provided care developed back pain and $16 \%$ of them developed hip pain [22]. In a study done recently, it was identified that $87.7 \%$ of those who cared for Alzheimer patients suffered from sleeplessness and nearly $80 \%$ of them had difficulty falling asleep [23]. When the studies on the burden of family members who provided care to cancer patients in Turkiye were examined, it was reported that $42.5 \%$ of the caregivers in the study of Yildız et al. (2016) and 54.5\% of the caregivers in the study of Özdemir et al. (2017) had fatigue [7], [24]. The vast majority of the family members participating in the study stated that while they cared for their patients, various diseases occurred or their existing diseases worsened, and they particularly experienced pain, sleep problems, and fatigue. It is thought that the most important reasons for family members in the palliative care unit experiencing physical problems are due to the lack of support systems in the family, lack of adequate social services, lack of information, and delaying their own health needs due to increased care burdens.

\section{Theme 2: Psychological Problems}

Findings are indicating that family members who continue the caregiving process have difficulties in providing care and experience many problems [5], [9], [14], [16]. These problems affect family members' lifestyle and cause adjustment issues and mental disorders [15]. In a recent study investigating the psychological burden of family members who care for palliative care patients, almost all of the caregivers were reported to experience psychological problems, and the five most frequent psychological problems they experienced were reported to be grief, sadness, anxiety, exhaustion and sleep disturbance [19]. In their study, Ullrich et al. (2017) found that $96 \%$ of family members who cared for palliative care patients experienced psychological distress and the most common emotions were sadness, grief, and burnout [9]. In the study done by Oechsle et al. (2019), it was found that $95 \%$ of the family members who provided care to advanced cancer patients who received palliative care suffered from stress [19]. To cope with feelings of loss affects family members emotionally. Besides, most family members who give care feel fear of the future because they think that the current condition of the patients will be worsened more and they will have more difficulties with their care needs that may increase [25]. It was determined that all of the caregivers who participated in our study were psychologically affected and generally experienced stress, depression, sadness, and fear. Our research result is similar to the ones found in the literature. It is thought that the most important reasons for primary caregivers to experience psychological problems are due to the fact that the individuals they care for are their mothers or fathers, they lack familial support systems, and they experience social isolation because they cannot fulfill their daily routines.

\section{Theme 3: Economic Problems}

Family members experience economic difficulties as a result of increased personal care, transportation, medication, and other care needs of the patient with a life-threatening disease [7]. Since the caregiver must spend most of the time with the patient, he/she may lose their job or change the way they work. Also, family members face economic difficulties as a result of high treatment costs and increased need for care [4-5]. In a qualitative study that investigated the problems and needs of the family of cancer patients receiving palliative care, a family member providing care stated that he did not have enough money and felt financially worse than ever despite receiving caregiver allowance and 
income support [26]. Özdemir et al. reported that many of those who provided care to cancer patients underwent changes in professional lives and more than $70 \%$ of them experienced economic problems [24]. Similarly, Nayak et al. reported that family members who provided care to cancer patients were unable to make time for their professional occupations and lost jobs during this process [27]. It was determined in this study that there are economic problems in line with the results in the literature, and the reason is thought to be the limited scope of the financial support provided to primary caregivers, job losses, and lack of information about the institutions they can get support from.

\section{Theme 4: Social Problems}

Because the risk of death and serious physical and cognitive disorders can be seen in patients admitted to the palliative care unit, health professionals rely on family members to provide $80 \%$ of the care given to patients to manage the adverse effects resulting from illness and treatment [3]. Giving care to a patient in the advanced stage is a full-time job, which takes all the energy and time of the caregiver [28]. The process of caring also affects family members' leisure activities, social relationships, friendship, and freedom [6]. In the study of Kalınkara and Kara (2017), it was determined that family members who cared for elderly patients did not have a social life, they lacked freedom, they gradually withdrew from social life and were isolated [29]. In the study of Harding et al. (2012), the majority of the caregivers stated that they had no personal time because they had to focus on the needs of the patient and they felt that they were in isolation and they did not have a life [26].

It was determined that all of the caregivers who participated in this study had problems with their social lives. It is believed that the most important reason for this is the absence of another person to provide care in the family and the lack of assistant personnel due to financial difficulties.

\section{Theme 5: Family Relationships}

Caregiving is generally accepted as a natural action imposed by the community and family members who take care of their relatives, with the belief that they fulfill a moral obligation [6]. In a study examining the effect of providing care to a patient in the terminal period on family members, caregiving activities caused an overall deterioration in the lives of $75 \%$ of the caregivers and this experience harmed their integrity [31]. Y1ldız et al. (2017) stated in their work that although many family members received support from other family members in this process, they still experienced financial difficulties due to care, and their family interactions were affected [7]. In another study that investigated the care burden of family members who provided care to cancer patients receiving chemotherapy, it was identified that $31.3 \%$ of the family members experienced negative changes in domestic relations [24]. Our study is also similar to the literature, and it was determined that the majority of caregivers had deteriorated family relationships during the caregiving process, and it is thought that these issues developed due to certain changes in family roles, psychological and financial difficulties brought about by the long-term care and the lack of social support systems.

\section{Conclusion}

It was determined in our study that family members who care for palliative care patients experience physical, mental, and financial problems; their home lives change because of arranging the home environment to suit the patient, their family relationships deteriorate, and their social interactions change because of the increase in their burden and responsibilities. The following strategies are recommended: providing treatment and care to such patients with an understanding of multidisciplinary teamwork, creating environments where the patient and family members can be with their loved ones 
while the patient receives this care, wholly assessing the needs of the family members who provide care at home while evaluating palliative care patients, providing information in detail about the care process, helping the patient create a plan in a way that does not prevent family members to go about their daily routines, getting help from home economists and ergonomists about changes in the home environment, directing family members to social support systems on financial matters, making sure that they receive psychological counseling services, therefore reducing their care burden, conducting large-scale studies that reveal the problems experienced by family members, and developing standard criteria and evidencebased guidelines to identify the problems and needs of family members.

\section{Acknowledgment}

The authors are grateful to all the participants in the study.

Ethical Consideration: Before data collection, Ethics committee approval was gained from the Ethics Committee of Non-Interventional Clinical Studies of Burdur Mehmet Akif Ersoy University (Decision Number: GO 2020/106; Date: 15.4.2020); written permission was obtained from the hospital administration where the research was conducted, and oral and written consent was also obtained from the family members, and information was given about the use of the voice recorder, and an assurance was provided about the confidentiality of the voice recording. Participant numbers were used instead of the names in the research report. This research was carried out by considering the Good Clinical Practices of the Helsinki Declaration.

The compliance to Research and Publication Ethics: This work was carried out by obeying research and ethics rules.

\section{References}

[1] Çolak, D., "Palliative care models around the world". Turkiye Klinikleri Anesthesiology Reanimation - Special Topics, 10(1), 13-9, 2017.

[2] Sarmento, V.P., Gysels, M., Higginson, I.J., Gomes, B, "Home palliative care works: but how? A meta-ethnography of the experiences of patients and family caregivers". BMJ Supportive \& Palliative Care, 7(4), 390-403, 2017. doi: 10.1136/bmjspcare-2016-001141.

[3] Goldsmith, J., Ragan, S.L., "Palliative care and the family caregiver: trading mutual pretense (empathy) for a sustained gaze (compassion)". Behavioral Sciences, 7(2), 19, 2017. doi: 10.3390/bs7020019.

[4] Kılıç, S.T., Öz, F., "Problems and quality of life of family members caring for cancer patients, and interventions". Journal of Hacettepe University Faculty of Nursing, 6(3), 197-204, 2019. doi: 10.31125/hunhemsire.630828.

[5] Naoki, Y., Matsuda, Y., Maeda, I., Kamino, H., Kozaki, Y., Tokoro, A., Maki, N., Takada, M., "Association between family satisfaction and caregiver burden in cancer patients receiving outreach palliative care at home". Palliative \& Supportive Care, 16(3), 260-268, 2018. doi: $10.1017 /$ S1478951517000232.

[6] Veloso, V.I., Tripodoro, V.A., "Caregivers burden in palliative care patients: a problem to tackle". Current Opinion in Supportive and Palliative Care, 10(4), 330-335, 2016. doi:10.1097/SPC.0000000000000239. 
[7] Yıldız, E., Dedeli, Ö., Çınar Pakyüz, S., "Evaluation of care burden and quality of life among family caregivers of patients with cancer". Journal of Education and Research in Nursing, 13(3), 216-225, 2016. doi: 10.5222/HEAD.2016.216.

[8] Robinson, J., Gott, M., Ingleton, C., "Patient and family experiences of palliative care in hospital: What do we know? An integrative review". Palliative Medicine, 28(1),18-33, 2014. doi: $10.1177 / 0269216313487568$.

[9] Ullrich, A., Ascherfeld, L., Marx, G., Bokemeyer, C., Bergelt, C., Oechsle, K., "Quality of life, psychological burden, needs, and satisfaction during specialized inpatient palliative care in family caregivers of advanced cancer patients". BMC Palliative Care, 16(1), 31, 2017. doi: 10.1186/s12904-017-0206-z.

[10] Córdova, M.I.P. de., Canales, R., Krederdt, S., Gutiérrez-Gómez, T., Hernandez, R.L., “The relationship of the quality of life and burden of informal caregivers of patients with cancer in Lima, Peru". Journal of Nursing Education and Practice, 6(8), 36, 2016. doi: 10.5430/jnep.v6n8p36.

[11] Silva, R.S. da., Trindade, G.S.S., Paixão, G.P. do N., Silva, M.J.P. da., "Family conference in palliative care: concept analysis". Revista Brasileira de Enfermagem, 71(1), 206-13, 2018. doi: 10.1590/0034-7167-2016-0055.

[12] Delalibera, M., Barbosa, A., Leal, I., "Circumstances and consequences of care: characterization of the family caregiver in palliative care". Ciência \& Saúde Coletiva, 23(4), 1105-17, 2018. doi: 10.1590/1413-81232018234.12902016.

[13] Ayabakan-Cot, D., Ates, E., Kurt, B., Nazlican, E., Akbaba, M., "Investigation of depression and quality of life factors in cancer patients' caregivers". Journal of the Balkan Union of Oncology, 22(2), 524-9, 2017.

[14] De Korte-Verhoef, M.C., Pasman, H.R.W., Schweitzer, B.P., Francke, A.L., OnwuteakaPhilipsen, B.D., Deliens, L., "Burden for family carers at the end of life; a mixed-method study of the perspectives of family carers and GPs". BMC Palliative Care, 13(1), 16, 2014. doi: 10.1186/1472-684X-13-16.

[15] Lee, C-Y., Lee, Y., Wang, L-J., Chien, C-Y., Fang, F-M., Lin, P-Y., "Depression, anxiety, quality of life, and predictors of depressive disorders in caregivers of patients with head and neck cancer: a six-month follow-up study". Journal of Psychosomatic Research, 100, 29-34, 2017. doi: 10.1016/j.jpsychores.2017.07.002.

[16] Tanco, K., Park, J.C., Cerana, A., Sisson, A., Sobti, N., Bruera, E., “A systematic review of instruments assessing dimensions of distress among caregivers of adult and pediatric cancer patients". Palliative \& Supportive Care, 15(1), 110-24, 2017. doi: $10.1017 / \mathrm{S} 1478951516000079$.

[17] Joseph, M.L., "Innovativeness in nursing: A phenomenological and constructivist study" [Doctoral Thesis]. Capella University, United States, 2007.

[18] Seekatz, B., Lukasczik, M., Löhr, M., Ehrmann, K., Schuler, M., Keßler, A.F.,Oorschot, B., "Screening for symptom burden and supportive needs of patients with glioblastoma and brain 
metastases and their caregivers in relation to their use of specialized palliative care". Supportive Care in Cancer 25(9), 2761-70, 2017. doi: 10.1007/s00520-017-3687-7.

[19] Oechsle, K., Ullrich, A., Marx, G., Benze, G., Heine, J., Dickel, L-M., Bergelt, C., "Psychological burden in family caregivers of patients with advanced cancer at initiation of specialist inpatient palliative care". BMC Palliative Care, 18(1), 102, 2019. doi: 10.1186/s12904-019-0469-7.

[20] Morrow, R., Rodriguez, A., King, N., "Colaizzi's descriptive phenomenological method". The Psychologist, 28(8), 643-644, 2015.

[21] Başkale, H., "Determination of validity, reliability and sample size in qualitative studies". Dokuz Eylul University E-Journal of Nursing Faculty, 9(1), 23-28, 2016.

[22] Schreiber-Katz, O., Klug, C., Thiele, S., Schorling, E., Zowe, J., Reilich, P., Nagels, K.H., Walter, M.C., "Comparative cost of illness analysis and assessment of health care burden of Duchenne and Becker muscular dystrophies in Germany". Orphanet Journal of Rare Diseases, 9(1), 210, 2014. doi: 10.1186/s13023-014-0210-9.

[23] Liu, S., Li, C., Shi, Z., Wang, X., Zhou, Y., Liu, S., Liu, J., Yu, T., Ji, Y., “Caregiver burden and prevalence of depression, anxiety and sleep disturbances in Alzheimer's disease caregivers in China". Journal of Clinical Nursing, 26(9-10), 1291-1300, 2017. doi:10.1111/jocn.13601.

[24] Özdemir, Ü., Taşci, S., Kartin, P., Çürük, G.N.Ç., Nemli, A., Karaca, H., "Functional status of chemotherapy receiving individuals and caregiver burden". Erciyes University Journal of Faculty of Health Sciences, 28;4(1), 49-61, 2017.

[25] Küçükgüçlü, Ö., Şentürk, S.G., Söylemez, B.A., "Experiences in the caregiving process of family caregivers of individuals with alzheimer's disease". Dokuz Eylul University E-Journal of Nursing Faculty, 10(2), 2017.

[26] Harding, R., Epiphaniou, E., Hamilton, D., Bridger, S., Robinson, V., George, R., Beynon, T., Higginson, I.J., "What are the perceived needs and challenges of informal caregivers in home cancer palliative care? Qualitative data to construct a feasible psycho-educational intervention". Supportive Care in Cancer, 20(9), 1975-82, 2012. doi: 10.1007/s00520-011$1300-\mathrm{z}$

[27] Nayak, M.G., George, A., Vidyasagar, M. S., Kamath, A., "Quality of life of family caregivers of patients with advanced cancer". IOSR Journal of Nursing and Health Science, 3(2), 70-75, 2014.

[28] Soner, S., Aykut, S., “Alzheimer's disease-processed caregiver family members difficulties and social work". Ahi Evran University Institute of Social Sciences Journal, 3(2), 375-387, 2017.

[29] Kalinkara, V., Kalayci, İ., "Life satisfaction, care burden and burnout of the individuals who have a caregiver service to the elderly at home”. Elderly Issues Research Journal. 9;10(2), 1939, 2017.

[30] Oğlak, S., "Social care: an ignored dimension of home care". Turkiye Klinikleri Public Health Nursing - Special Topics, 2(3), 32-7, 2016. 